\title{
Meaning-in-Life: A Vital Salutogenic Resource for Health
}

\author{
Gørill Haugan and Jessie Dezutter
}

\begin{abstract}
Based on evidence and theory, we state that facilitating and supporting people's meaningmaking processes are health promoting. Hence, meaning-in-life is a salutogenic concept.

Authors from various disciplines such as nursing, medicine, psychology, philosophy, religion, and arts argue that the human search for meaning is a primary force in life and one of the most fundamental challenges an individual faces. Research demonstrates that meaning is of great importance for mental as well as physical well-being and crucial for health and quality of life. Studies have shown significant correlations between meaning-inlife and physical health measured by lower mortality for all causes of death; meaning is correlated with less cardiovascular disease,
\end{abstract}

G. Haugan $(\bowtie)$

Department of Public Health and Nursing,

NTNU Norwegian University of Science and Technology, Trondheim, Norway

Faculty of Nursing and Health Science,

Nord University, Levanger, Norway

e-mail: gorill.haugan@ntnu.no,

gorill.haugan@nord.no

J. Dezutter

Meaning Research in Late Life Lab, Faculty of

Psychology and Educational Sciences, KU Leuven,

Leuven, Belgium

e-mail: jessie.dezutter@kuleuven.be less hypertension, better immune function, less depression, and better coping and recovery from illness. Studies have shown that cancer patients who experience a high degree of meaning have a greater ability to tolerate bodily ailments than those who do not find meaning-in-life. Those who, despite pain and fatigue, experience meaning report better quality-of-life than those with low meaning. Hence, if the individual finds meaning despite illness, ailments, and imminent death, wellbeing, health, and quality-of-life will increase in the current situation. However, when affected by illness and reduced functionality, finding meaning-in-life might prove more difficult. A will to search for meaning is required, as well as health professionals who help patients and their families not only to cope with illness and suffering but also to find meaning amid these experiences. Accordingly, meaning-in-life is considered a vital salutogenic resource and concept.

The psychiatrist Viktor Emil Frankl's theory of "Will to Meaning" forms the basis for modern health science research on meaning; Frankl's premise was that man has enough to live by, but too little to live for. According to Frankl, logotherapy ventures into the spiritual dimension of human life. The Greek word "logos" means not only meaning but also spirit. However, Frankl highlighted that in a logotherapeutic context, spirituality is not pri- 
marily about religiosity—although religiosity can be a part of it-but refers to a specific human dimension that makes us human. Frankl based his theory on three concepts: meaning, freedom to choose and suffering, stating that the latter has no point. People should not look for an inherent meaning in the negative events happening to them, or in their suffering, because the meaning is not there. The meaning is in the attitude people choose while suffering from illness, crises, etc.

\section{Keywords}

Freedom to choose $\cdot$ Health $\cdot$ Human values Meaning-in-life $\cdot$ Meaning-making $\cdot$ Spiritual care $\cdot$ Spirituality $\cdot$ Suffering $\cdot$ Well-being Will to meaning

\subsection{Meaning-in-Life: A Multi- Layered Concept}

The experience of meaning is central to humans [1-3] and has become one of the core facets of the positive psychology movement [3] as well as of the health promotion field. In general, meaning has been found to be a strong individual predictor of life satisfaction [4-6] and an important psychological variable that promotes well-being [7-9] and protects individuals from negative outcomes $[10,11]$. Meaning seems to serve as a mediating variable in psychological health [12-16].

In literature there is a distinction between (1) meaning-of-life and (2) meaning-in-life. The first concept pertains to the question of the significance of human existence in general. This question is discussed by a range of existential philosophers, such as Soren Kierkegaard, Albert Camus, and Friedrich Nietzsche, who wanted to explore whether and how the existence of human beings has meaning over time. The second concept refers to the individual's perceived meaningin-life; the question is no longer focused on the more abstract and general meaning of human life but is scaled down to the question whether you experience your own individual life as meaning- ful. This topic is more recently a focus of interest of psychologists, nurses, and health practitioners receiving increasing attention in the health literature. However, meaning-in-life is a subjective and personal phenomenon that is difficult to define.

One of the prominent scholars in the field of meaning is psychiatrist Victor Emil Frankl. Although he mainly refers to purpose-in-life (PIL) and not to meaning-in-life, his description of these concepts clearly overlaps. Purpose-inlife as a concept originates from Frankl's writings about the "will to meaning" as the primary motivational force for survival; he stated that meaning is a motivational and vitalizing force in humans' lives [17-19]. To find personal meaning involves understanding the nature of one's life, and to feel that life is significant, important, worthwhile, or purposeful (ibid.). In Frankl's theory, meaning is a broad construct that is conceptually and empirically related to many domains; positive associations of meaning are found in relation to constructs such as hope, faith, subjective well-being, and happiness, as well as negative associations between meaning and depression, anxiety, psychological distress, boredom, proneness, and drug/alcohol use [3, 9, 20, 21]. Frankl's theory of meaning termed logotherapy has been used as a basis for research and practice in many fields, including medicine, psychology, counseling, education, ministry, and nursing [22].

The concept of meaningfulness is also crucial in the salutogenic health theory of the sociologist Aaron Antonovsky, which is termed salutogenesis $[23,24]$. In this model, he focused on healthpromoting resources, among which sense of coherence (SOC) is a vital salutogenic resource in people's lives. Antonovsky defines SOC as a global orientation to perceive the world as comprehensible, manageable, and meaningful despite the stressful situations one encounters. Individuals with a strong SOC tend to perceive life as being manageable and believe that stressors are explicable. People with a strong SOC have confidence in their coping capacities [25]. Several studies link SOC with patient-reported and clinical outcomes such as perceived stress and coping [26], 
recovery from depression [25], physical and mental well-being [27], satisfying quality-of-life (QoL), and reduced mortality [28, 29]. SOC has thus been recognized as a meaningful concept for patients with different medical conditions.

Meaning-in-life is furthermore a vital aspect in the work of the existential psychotherapist Irvin Yalom [30]. According to Yalom, all individuals experience core anxieties or existential concerns related to their existence. He focuses on four main concerns: (1) the inevitability of death, (2) the freedom to shape our own lives, (3) our ultimate aloneness, and (4) the absence of any obvious meaning-in-life. For Yalom, meaninglessness is an existential given and cannot be solved. An individual's sudden realization of meaninglessness can be compared with an experience of total groundlessness. Yalom assumes that meaninglessness is present in everybody's life as well as in every therapy. More recently, meaning-in-life has become a topic of interest for empirical psychologists. The abstract nature of this concept, however, makes a clear conceptualization difficult, and the concept has therefore been defined in myriad ways. Steger [31], one of the leading scholars in this field, stated that people experience meaning when they comprehend who they are, what the world is like, and if they understand their unique fit in the world. Meaning is also described as an individual's sense that his/her life has value, direction and purpose, and that he/she belongs to something greater than the self, adding a sense of "belonging" [32]. In a cognitive perspective, meaning is described as a "mental representation of possible relations among things, events and relationships" [33] (p. 15), while others highlight the intuitive feeling that things make sense [34]. Some researchers have tried to disentangle meaning-in-life from purpose-in-life [35], whereas others defined purpose as part of meaning-in-life [36] or stressed that having goals or life aims are central aspects of meaning-in-life [37].

Although a comprehensive, unified framework of meaning is lacking, Martela and Steger [38] recently proposed a first theoretical step toward integrating the main aspects of meaning; they delineate three components within the construct which capture much of the variance in the past definitions, namely (1) coherence, (2) purpose, and (3) significance (tripartite view) [38]. Looking at these components, the connection to the salutogenic health theory emphasizing comprehensibility, manageability, and meaningfulness seems clear. (1) Coherence refers to a cognitive aspect that one's life makes sense; it reflects a sense of comprehensibility in life and is situated in the domain of "understanding" [38]. (2) Purpose refers to a motivational aspect indicating that individuals have future-oriented longterm goals and feel that their lives have direction [17]. Purpose reflects the pursuit and attainment of core aims, ultimate life goals and aspirations for life [36]. (3) Significance refers to "the degree to which individuals feel that their existence is of significance and value" [39] (p. 2); that is a feeling of "existential mattering," having a life worth living. Although this tripartite view on meaningin-life is promising in providing in-depth insight into the phenomenon of meaning in people's lives, research validating this structure of meaning is virtually absent (see George \& Park, 2016 for one available study in a population of psychology students).

Since Frankl's theory of the "Will to Meaning" has been used as a basis for research and practice in many fields, including medicine, psychology, counseling, education, ministry, and nursing [22], in the next section this chapter presents Frankl's logotherapy.

\subsection{Frankl's Theory: The "Will to Meaning"}

Viktor Emil Frankl, psychiatrist and survivor of the Nazi concentration camps, assumed that meaning is of crucial importance to men. Based on the horror Frankl experienced in the camps, he concluded that everything can be taken away from men, from belongings and health to loved ones, but nobody can take away men's will to experience meaning. Frankl [17] described the process of "will to meaning" as a search process. He defined searching for meaning as "the pri- 
mary motivational force in man" (p. 121), and a natural, healthy part of life.

Although Frankl developed his theory in the field of mental health and psychiatric diseases, the scope has been expanded and the theory is now considered relevant also to people who, for various reasons, struggle with everyday stress, disasters, losses, and crises. Today, this theory is applied not only on the individual level but also on the group level. During Frankl's working life in Europe, a set of concepts and the connection between them were referred to as a "school" and not as a theory, as we do today. As a professor of psychiatry and neurology, Frankl studied the "first Viennese school" in psychotherapy known as "The Will to Pleasure" exposed by Freud. Later, Adler developed the "second Viennese school" "The Will to Power." Frankl [19] recognized both schools, but still he believed that

\begin{abstract}
man can no longer be seen as a being whose basic concern is to satisfy drives and gratify instincts or, for that matter, to reconcile id, ego and superego; nor can the human reality be understood merely as the outcome of conditioning processes or conditioned reflexes. Here man is revealed as a being in search of meaning-a search whose futility seems to account for many of the ills of our age. (p. 17)
\end{abstract}

Thus, Frankl called his theory "The Will to Meaning," which became known as the "third Viennese school." The term "meaning" used in modern health science originates from Frankl's theory of will to meaning as the strongest driver of mental and physical survival. Experience of meaning represents a vitalization in everyday life [19], a primary force that involves understanding who one is, feeling important and valuable to oneself and others, and finding meaningful goals and purposes in one's life. In Frankl's theory, meaning is a broad concept that is theoretically and empirically related to several different dimensions; studies have shown that meaning is positively related to concepts such as hope, belief, well-being, happiness, and global QoL, while meaning is negatively related to depression, anxiety, psychological stress, boredom, and substance abuse [3, 9, 20, 21].

Frankl's logotherapy has its roots in a phenomenological understanding of human beings with existential needs, consciousness, and values [87]. Through experience from several years in Hitler's concentration camps and his many years of work as a psychoanalyst, Frankl had the following starting point for his theory: "people have enough to live by, but not enough to live for." Therefore, the individual does not tolerate stress. The key to coping with adversity and suffering lies in the fact that the individual finds meaning-in-life, day by day, year after year. Frankl claims that anyone who knows why he lives, e.g., the value of just being here, can withstand many hardships. Nonetheless, it is important to mention that Frankl was frustrated that his logotherapy was solely related to his experiences in four different concentration camps during World War II, while the ideas and essences of this theory were developed well before the war. He just had no time and opportunity to write them down. Anyway, the experience of Hitler's concentration camps became a validation of his "will to meaning."

According to Frankl [17, 19], logotherapy ventures into the spiritual dimension of human life. The Greek word "logos" means not only meaning but also spirit. Accordingly, in the early Greek language, there is a connection between spirituality and meaning. Frankl highlighted that in a logotherapeutic context, spirituality is not primarily about religiosity - although religiosity can be part of it-but refers to a specific human dimension that makes us human. The need for meaning arises from the individual's existential consciousness of mortality; one day death will come. Frankl considered an individual's conscience as the "body-of-meaning" [19]. Conscience is closely related to the individual's values, morals, responsibilities, and integrity and is an intuitive, creative, and central force in the human quest for meaning in any given situation. Conscience is thus a subjective dimension, closely linked to cultural and national values, norms, and rules that apply in the context of the individual person. It is the individual's task to decide whether to interpret his or her life's tasks based on accountability to society, to God, or to his own value system. Human beliefs, values, and integrity are crucial to what can provide meaning to the individual. 


\subsubsection{Three Substantial Concepts of Frankl's Theory Will to Meaning}

Frankl's theory is based on three substantial concepts: (1) meaning-in-life, (2) freedom to choose, and (3) suffering. Furthermore, these three concepts are linked to three basic assumptions in humans' lives: (1) the physical body, (2) the mental mind containing emotions and thoughts, and (3) the spiritual, or what Frankl calls "noos" [17]. The physical body and mental mind can become ill, while the human spirit can become blocked and frustrated. Frankl believed that the three dimensions of body-mind-spirit are parts that act as a unified totality. That is, problems in one dimension often cause symptoms in another. For example, spiritual emptiness can be manifested as a physiological symptom such as a headache. To understand Frankl's theory, one must understand his emphasis on the human spirit, "the noos," and its vital role in the individual as an integrated unit of these three: body-mind-spirit. This corresponds well with modern nursing theory $[68,88]$ and recent research that indicates that people function as a unit where body-mindspirit is fully integrated with each other and are inseparable [89]. Figure 8.1 illustrates that the body-mind-spirit levels act as parts that, through constant and infinite interaction between each other, represent an inseparable entity. The dotted circles in Fig. 8.1 illustrates the integral interaction between the body-mind-spirit parts.

\subsubsection{Meaning-in-Life}

The term meaning involves the answer to man's existential questions: "Who am I?" and "Why am I here?" The experience of purpose and meaning produces positive emotions such as satisfaction with one's place in the world. Perceived meaningin-life relates to what the person feels dedicated to, to provide one's unique contribution to a better world bestows purpose and meaning. A purpose-in-life represents a direction of one's energy, as well as a driving force in the individual's quest for meaning; this idea is key in Frankl's theory. Meaning is discovered and determined from the uniqueness of the individual person and

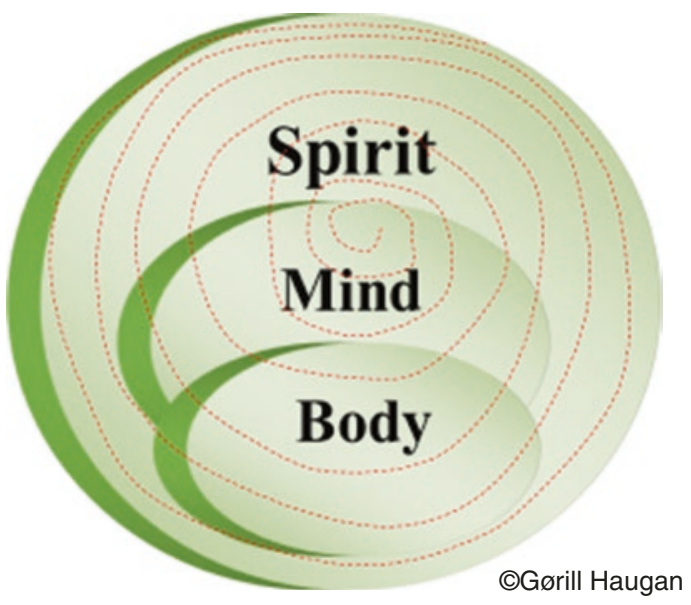

Fig. 8.1 The unity of body-mind-spirit in which steadily ongoing integrating processes unify the parts into one inseparable entity

his/her specific life situation. Frankl argued that meaning always changes, but never ceases to be potentially present.

Finding meaning-in-life is a subjective and unique process that takes place in the individual's mind. Meaning can neither be invented nor given as a gift. Meaning must be revealed by the individual. Thus, it is not possible for health care professionals to "tell" or "teach" the patient how to find meaning. Nor can health workers create, point to, or transfer meaning to another; finding meaning-in-life requires an inner process and active effort by the individual. Health care workers can "walk along with" the one searching for meaning, listening, asking questions, and challenging. Scholars differ in their perspectives on how meaning can be attained. Some stress that meaning needs to be discovered by the individual, implying more automatic processes, whereas other stress that the process is more deliberate and conscious, and they accordingly refer to meaning-making or meaning constructing [74]. Realizing meaning-in-life is closely related to realizing oneself. Frankl [17] argued that what people have been able to accomplish, endure, and master earlier in life represents a source of meaning here-and-now: "All we have done, whatever great thoughts we may have had, and all we have suffered, all this is not lost, though it is past; we have brought it into being. Having been is also a 
kind of being and perhaps the surest kind" (p. 104). It is possible to distinguish between "meaning in the moment" which relates to the choices people make at any time in their daily lives and a "universal meaning", which is about the big picture and a confidence that there is some form of order in the universe which we are a part of. A universal meaning represents the opposite of a chaotic world where humans are victims of random impulses. The concrete thing that makes sense here-and-now may shift but is always there as an opportunity to be discovered.

Frankl [17] outlined three different sources of meaning: (1) performing good deeds or actions; to give or contribute something good or useful, or by one's creativity to create something beautiful; (2) experiencing something valuable, beautifulexperiencing goodness and loving fellowship; and (3) realizing dignified, honorable, and positive attitudes in the face of life's challenges, such as illness, suffering, and death. Hence, it seems clear that the phenomenon of self-transcendence (about self-transcendence, see Chap. 9 in this book) is closely related to purpose and meaning-in-life $[17,19,90]$. Self-transcendence refers to the ability to transcend oneself; an opening to something greater outside oneself [91]. It can be about doing a job, an effort, realizing a virtue; despite one's own life situation being demanding, painful, and difficult, to extend beyond one's self-occupation in the ego. Thus, self-transcendence implies a strategy for creating distance to oneself and one's own situation, and thereby provide a mindset without focus on one's troubles and worries. A self-transcended approach gives the opportunity to see and experience one's situation from a different perspective, and therefore an opportunity to find solutions and meaning amid the difficult and painful. For example, we have seen that parents who have lost a child in the crib have started the National Association for Unexpected Child Death to be able to help other parents in the same situation. Several similar examples exist.

Being open for other people's kindness and love does also provide an experience of meaningin-life. Social support relates closely to the perception of meaning [49], while negative interaction with others can reduce perceived meaning-in-life [49, 92-95]. Furthermore, research has shown that positive emotions and moods appear to be a stronger source of meaning than activities toward achieving certain goals [1].

According to Frankl, the third strategy for people to create meaning-in-life is, despite any life challenges, to consciously choose their attitudes. Choosing to be positive, courageous, or optimistic despite difficult and painful events illustrates this strategy for meaning. Experience of meaning can arise from the patient voluntarily changing his attitude and consequently his perception of his current life situation.

Man's will to meaning can be frustrated, disappointed, or unfulfilled; Frankl called this "existential frustration" and "existential vacuum." When people feel despair and when they struggle to experience life as worth living, this is not an expression of mental illness, but of spiritual distress. According to Frankl, the health system often interprets and diagnoses spiritual distress as a mental illness (e.g., depression), and thus treats the condition by anesthetizing the patient's existential despair with medication. Existential vacuum is expressed by feelings such as meaninglessness, emptiness, apathy, and boredom [96] and can lead to severe neurosis. This neurosis is caused by spiritual frustration or problem, moral or ethical conflicts, existential vacuum, or frustrated will to meaning.

\subsubsection{Freedom to Choose}

Freedom to choose constitutes the second term in Frankl's logotherapy and is closely linked to the above-described sources of meaning. Many people are confronted with an undesirable fate, such as Holocaust, tsunamis, earthquakes, etc. In dealing with such life events, one can only be accepting - there is no use fighting - it is just about choosing one's attitude. Frankl [17] wrote that "the way in which he accepts, the way in which he bears his cross, what courage he manifests in suffering, what dignity he displays in doom and disaster, is the measure of his human fulfillment" (p. 44). Humans can be subjected to torture and humiliation, to illness, destruction, loss and death, and yet choose to meet their destiny with courage and humanity. The sufferer's attitude is the 
motivating force for his actions, not the torturer. The right to choose one's attitude is regarded as human spiritual freedom and mental independence. The freedom of the will is about freedom to choose attitude regardless of external situation and circumstances. The individual cannot free himself from the conditions under which he lives. Still, he can consciously choose his attitude toward these conditions. The expression "will to meaning" indicates that meaning-in-life does not come "fleeting on a foal"; meaning does not come by itself, but requires effort, a desire and a conscious choice to actively search for meaning.

\subsubsection{Suffering}

The third concept of Frankl's theory is suffering, which represents a subjective, unique, and personal experience. Suffering is an inevitable part of humans' lives on earth. We are exposed to incidents that are undeserved, incomprehensible, and inexplicable as well as inevitable. The suffering is. It exists. At this point Frankl was quite clear; suffering has no point. There is no point in getting cancer or losing a child in an accident. Thus, people should not look for an inherent meaning in such events, because the meaning is not there. The meaning is in the attitude we choose while suffering. For example, a cancer patient chooses a positive and caring attitude toward others despite his own illness and need of care. That is, despite cancer and major losses, it is possible to realize meaning. Frankl [19] wrote about his experiences in concentration camps during World War II: "We who lived in concentration camps can remember the men walking through the huts comforting others, giving away their last piece of bread. They may have been few in number, but they offer sufficient proof that everything can be taken from a man, but one thing: the burden of human freedoms - to choose one's attitude in any given set of circumstances, to choose one's own way" (p. 86). Figure 8.2 illustrates the relationship between these three concepts in Frankl's Theory "Will to meaning." The individual experiences suffering in different ways; suffering is a personal and subjective experience of distress which impacts the individual as body-mindspirit negatively. Frankl highlighted that the meaning is not in the suffering itself. Only by means of one's freedom to choose actively one's

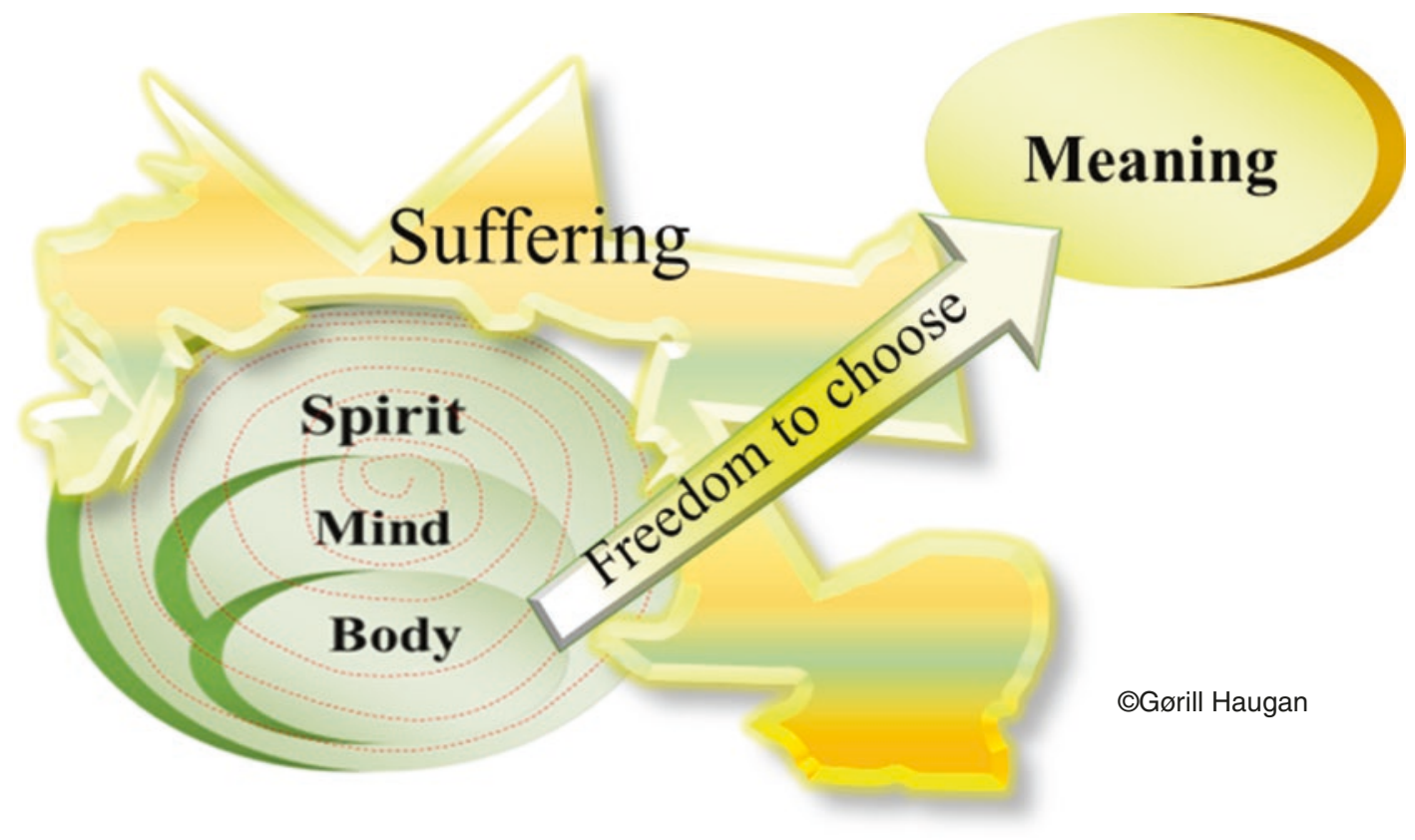

Fig. 8.2 Frankl's theory the "Will to meaning": Three central concepts and their relationships with each other 
attitude, way of thinking, and how to approach one's life situation, meaning can be found. According to evidence and theory, we have shown that those who despite illness, crisis, suffering, etc. find meaning are better able to comprehend and manage the situation, and report better QoL and wellness.

\subsection{Meaning-in-Life and (Mental) Health}

Empirical studies seem to confirm that the experience of meaning is related with well-being and optimal health, representing an important resource when adjusting to or recovering from an illness [36, 40]. Accordingly, experiencing meaning-in-life is regarded as a highly desired psychological quality ("my life is meaningful") (ibid.). Positive associations between meaningin-life and psychological well-being have been found across the lifespan, including adolescence [41], emerging adulthood [42], midlife, and older adulthood [40, 43]. The experience of meaningin-life seems fundamental to humans [1, 2, 44] and is of significance in health and well-being particularly in later years [45-47]. Studies have shown significant correlations between meaningin-life and physical health measured by lower mortality for all causes of death; meaning is correlated with less cardiovascular disease, less hypertension, better immune function, less depression, and better coping and recovery from illness [48-53]. This might indicate that if the individual finds meaning despite illness, ailments, and imminent death, well-being, health, and QoL will increase in the current situation. However, plausibly the relationship also goes the other way; when affected by illness and reduced functionality, finding meaning-in-life might prove more difficult [54].

Among cancer patients, symptoms related to psychological and existential discomfort are as prominent as pain and other physical ailments. Studies have shown that cancer patients who experience a high degree of meaning have a greater ability to tolerate bodily ailments than those who do not find meaning-in-life; those who, despite pain and fatigue, experience meaning report better QoL than those with low meaning $[55,56]$. Meaning is seen as a buffer that contributes to inner strength and thereby protects terminally [57] and critically ill [58, 59] patients from depression, hopelessness, and the urge to give up and desire an accelerated death. In a sample of chronic pain patients, for example, higher levels of experienced meaning-inlife predicted lower levels of depressive symptoms 1 year later [60]. Depression and hopelessness-contrary to meaning-are associated with increased mortality, dramatically higher suicide rates, and the desire for a physician-assisted death. In this context, some authors speak of a "demoralizing syndrome" [61, 62] that can occur in terminal patients when the disorder bodily-psychological-existential becomes intolerable and one's existence seems meaningless. Perceived meaning has also shown to have a strong impact on physical well-being in nursing home residents [40] and seems to moderate the relationship between illness, ailments, and functional loss on the one hand and QoL and well-being on the other.

Furthermore, research demonstrates that older people experience less meaning than other age groups [63]; on the contrary, some studies show that older people experience more meaning [42], whereas research among very old adults (85-95 years) shows that meaning declines with very high age [64]. However, meaning is suggested as a good indicator for older adults to cope well with the aging process and its consequences [65, 66].

Nevertheless, studies show that meaning correlates highly with ailments, symptoms, and reduced functionality [54]; all of which are commonly present among patients, old, or young, in the health services. Regardless of patients' age, diagnosis and gender, perceived meaning-in-life is important in clinical health care and research. Frankl's theory of meaning has been used as a basis for research and practice in many fields [22]; this chapter focuses on nursing and health science. 


\subsubsection{Meaning-in-Life: A Salutogenic Concept in Nursing and Health Science}

Meaning-in-life is increasingly addressed in nursing and health literature $[22,67]$, underpinning the importance of nurses and health professionals to help patients and their families not only to cope with illness and suffering but also to find meaning in these experiences (event-related meaning) and to experience their lives as meaningful (meaning-in-life) despite the disease or illness $[22,68,69]$. Meaning seems vital in coping with severe health stressors. This is conceptualized clearly in the meaning-making model of Crystal Park [70] which proposes that people possess a global meaning system, including beliefs, goals, and a subjective sense of purpose. This global meaning system functions as an orienting system, providing individuals with a framework to interpret life experiences [71]. Stressful events impact on the meaning-making system, causing a discrepancy between the appraised situation and the global meaning system. This discrepancy creates distress, initiating a process of meaning-making. As part of the meaning-making process, both cognitive (i.e., reappraisal, rumination [72]) and emotional strategies (i.e., emotional processing [73]) can be activated. The end-products of this meaningmaking process ("meaning made" [74]) can be operationalized as benefit finding (i.e., finding positive implications for a negative event) or sense-making (i.e., finding a suitable explanation for a negative event within the global meaning system). A successful resolution of the meaningmaking process will then lead to better psychological functioning and better adjustment to stressful events [75].

This is in line with the salutogenic perspective of Antonovsky [76]. He described "sense of coherence" (SOC) as a measure of an individual's capacity to use various coping mechanisms and resources when faced with a stressor. Individuals with a strong SOC are assumed to effectively handle stress and maintain health, despite extremely challenging circumstances. After interviewing concentration camp survivors,
Antonovsky concluded that individuals' ability to stay healthy despite severe circumstances is related to the way they view their life and their existence [28]. He assumed that three aspects are important in this life view: the ability to understand what happens around them (comprehensibility), the ability to manage their situation (manageability), and their ability to find meaning in their situation (meaningfulness). Several studies have indeed shown that SOC is vital to coping with life's stresses such as illness, loneliness, despair, anxiety, and death [77-80].

Paying attention to meaning-in-life or to event-related meaning within care is also a focus of the bio-psycho-social-spiritual model of care as it developed by Sulmasy [81]. He argues that a person is a being in relationships and that illness involves a disruption of these relationships. Care needs to focus on restoration of the disturbed relationships. This restoration does involve not only biochemical and physiological processes (physical) but also mind-body relationships (psychological), relationships with the environment (social), and the relationship between the patient and the transcendent. This is in line with theorizing of Dossey and Keegan [68] who refer to the spiritual dimension of man as completely interwoven with the body, mind, and emotions (ibid.); that is, the human body, mind, and spirit are fully integrated with each other and constitute an indivisible whole. Bottom line, if the body is influenced, the mind and spirit will be affected at the same time. Every experience will therefore involve all dimensions of the individual: the physical, emotional-mental, social, and the spiritual-existential [82]. The holistic perspective thus emphasizes a sound integration or balance between the body-mind-spirit as crucial for health, well-being, and QoL. When discussing illness and care, Sulmasy [83] and others add the existential domain as an important fourth layer but with a focus on the transcendent (biopsychosocial spiritual model). A transcendental relationship with the divine is, however, not the only approach for the confrontation with meaninglessness [84]. Recent studies show that individuals, especially in West- and North-European secularized countries, also construct meaning based on 
secular sources such as altruism, selfactualization, family or work without the reference to spirituality or a religion [85]. Indeed, pain patients can turn toward spirituality in their search for meaningfulness, but they can also tap into other sources. A biopsychosocial existential model seems therefore more adequate when studying the influence of pain on all domains of life. In a Flemish study of chronic pain patients, patients reported not feeling satisfied with the attention to the social and existential life domains. Furthermore, practitioners' attention to the existential domain seems highly important for patient functioning [86]. Openness to existential concerns of pain might thus be an important aspect of care and nursing practice. The theoretical and therapeutic framework of Viktor Emil Frankl can be very useful in this vein.

\subsection{To Promote Meaning Is to Promote Health}

Currently, depression is the most prevalent disease worldwide [97]. This has many explanations and reasons. Frankl approached depression as a potential meaning-in-life problem and described the existential vacuum as early as in the 1960s. During the recent decades, suicides, divorces, alcoholism, intoxication, and criminality among adolescents have increased globally. Also, a growing tendency of overeating, overtraining, overworking, etc. has become evident. Frankl saw this as the result of people's attempts to cope with a lack of meaning; that is a lack of selfesteem, self-understanding, and meaningful realistic goals and purposes in life. Inspired by Frankl's logotherapy, different intervention approaches have been implemented to treat depression and anxiety [56, 98-101].

\subsection{1 “Not How Your Situation Is, But How You Respond to It"}

Research has so far demonstrated that people's well-being far more related with an individual's subjective perception/interpretation and evalua- tion of his/her objective conditions in life, than with the objective conditions per se. Consequently, personality and personal characteristics are important. Is there a personality, a gene related with greater sense of meaning-inlife? There is no doubt that personality and personality traits matter [102]. However, studies also show that therapy, cognitive, and spiritualmental techniques such as gestalt therapy, cognitive therapy, mentalization, yoga, meditation, mindfulness, and prayer can have a positive impact on meaning-in-life and hence on mental health [40, 54, 82, 103, 104]. Being a living human comprising a unified trinity of bodymind-spirit implies steadily ongoing natural healing processes; inherent natural processes work toward homeostasis, growth, development, and healing. Humans represent inner energies that constantly integrate and heal the unity body-mind-spirit throughout life. Therefore, facilitating and supporting people's meaningmaking processes represent to support and facilitate these inner processes toward healing. Hence, supporting meaning is health promoting.

\subsubsection{To Facilitate and Support Patients' Search for Meaning}

Health care professionals can facilitate and support patients' search for meaning by offering a relationship where the patient as a unique person can be acknowledged, welcomed, and respected $[11,105]$ : that is, a space of trust and confidence in which the patient feel free and relaxed, without feeling the need to care for the other. For example, the terminal husband's desire to care for and protect his wife's feelings, resulting in holding himself back keeping his innermost and heaviest thoughts and troubles by himself. Or when a child is seriously sick and dying; in care for the parents and the sick sister/ brother siblings hold their feelings back, suffering silently alone, etc. The examples are many. Professionals can provide a relational spot in time and space, in which only the dying husband's or the suffering sibling's experiences and feelings are attended to. Finding meaning is 
about knowing who one is and why one is alive; e.g., what one lives for. Reflections on what life has been like, the individual's experiences of values and good things in life are sources of meaning and can also enhance a sense of connection. Communicational approaches in such situations may be questions such as "Are there periods in your life which you experienced particularly meaningful?" "Do you know anyone who lives a meaningful life?" "Are there people in your life who need you?" "Will you tell about an experience that made you think differently about life?" "Have you ever thought that 'I can't do this', and yet you did and experienced that you managed to do it?"

\subsubsection{To Encounter Suffering and Negative Feelings}

Often, health care professionals encounter patient's anxiety and concerns, perhaps guilt, remorse, and bad conscience, because the person feels that what he/she did in life was not good enough; it should have been better, the children should have had a better parent, etc. In such situations, health promotion is about listening with respect and acceptance to what the person tells [95, 105], without being tempted to comfort. Commonly, health care professionals tend to comfort. Instead of actively and empathically listening, they start to communicate that "Oh, you should not think like that, you should not be so harsh on yourself; do not think that way, you should rather focus on all that is good in your life," etc. By doing so, though with a good intention, health care professionals fail the person who shares his feelings and thoughts. This failure is not health promoting. Failure involves neither social nor emotional support. But listening with respect, acceptance, and attention, confirming that you acknowledge the patient's experience and recognize what really matters to him here and now, that is emotional support and health promoting $[89,94,106]$. The fact that someone is willing to be a witness, to recognize, acknowledge, endure, and pay attention, is itself health promoting [107]. When the professional does not escape but stays present, tolerates, and accepts, the patient is not left alone in the pain and hardship. Feeling abandoned gives a feeling of loneliness, which in turn amplifies despair and pain [108].

Therefore, health professionals should develop a set of "muscles" that help to bear and endure patient's suffering; "muscles" which can withstand human's painful feelings and thoughts, which are strong enough to tolerate and accept what is expressed by the patient. Acknowledge, accept, endure, and attend to it. This is how health care professionals can contribute to meaning-inlife, by facilitating feelings of being tolerated, welcomed, and accepted. In this way, patients may experience a living space of acknowledgment, understanding, and thus connectedness, facilitating acceptance of oneself and one's life as it is [89, 105, 109]. By providing inner peace, tranquility, and releasing energy for positive aspects of life here-and-now, acceptance is healing and health promoting [105, 110, 111]. Asking questions, listening actively, supporting the patient to explain a bit more about his experiences and feelings may foster the patient's selfawareness, supporting his understanding of himself here-and-now, and what provides meaning in the present situation (about nurse-patient interaction as a salutogenic resource; see Haugan, G. (2021), Chap. 10 in this book).

The same applies in the care of terminally or critically ill patients who sometimes, in despair and exhaustion, wish to give up on life, asking for euthanasia. Health professionals need a mental "musculature" that can withstand suffering, despair, and desperation, without wanting to "fix" it, intending to change the patient focus into a more positive one. This is often framed “misunderstood comfort." In general, health professionals are trained to cure, and their main focus is therefore curing the disease. But in several situations, curing is no longer an option, and there needs to be shift to healing. Finding meaning in the event or regaining meaning despite the disease can be a pathway to healing. To support and facilitate meaning and thereby the relief of despair, it is first needed to be able to recognize and endure the patient's despair, pain, and hopelessness. From this experience, he may be able to lift his eyes looking at something brighter. 
Containing other people's despair and desperation is burdensome and an intense work. To cope with this, a fit "musculature", self-understanding, and a health-promoting working culture are needed.

\subsubsection{To Arrange for Health- Promoting Communities and Companionships}

If possible, health care workers can arrange for the patient to experience health-promoting companionship, with the patient's friends, family, or peers in the ward. Many patients in hospitals are waiting for a diagnosis, feeling insecure, worrying about what might be wrong with them. Many get a serious message from the doctor about their health state: "you have cancer," "you have ALS" (amyotrophic lateral sclerosis), "you have MS" (multiple sclerosis), "your leg must be amputated," "the needed surgery is risky," etc. Diagnoses most often involve challenges and high demands on endurance and coping. Helping the patient to perceive the situation as understandable and manageable will contribute to increased meaning and a sense of coherence, both of which promoting coping and mental health [112-114]. Individually adapted and repeated information accompanied with emotional and practical support serve as a buffer of meaning in demanding life situations. Undergoing medical examinations and treatment is often a major burden for the patient; for him, this is most often new, frightening and overwhelming, while for the health care professionals, the various medical examinations and treatments might be commonplace. Therefore, it is crucial that professionals are aware of their attitudes toward various activities carried out during a working day in the hospital.

\subsection{Conclusion}

This chapter outlines the main ideas of the Austrian psychiatrist and neurologist Viktor Emil Frankl's theory of meaning, termed logotherapy. Research shows that meaning is essential for mental health and psychological as well as physi- cal well-being and serves as a buffer and coping resource. This chapter demonstrates the significance of finding purpose and meaning-in-life as a resource to continue life amid great stress. However, meaning does not appear by itself; individuals need a "will to meaning," to consciously search for the unique meaning that is potentially present in any situation. Patients are often subjected to great stresses such as serious illness, painful medical examinations, and demanding treatments, as well as loss, grief, despair, and desperation. Finding meaning in these situations can be difficult. Nevertheless, studies show that patients who find meaning can tolerate symptoms, the disease, and its various outcomes better than those with low meaning. Thus, to support and facilitate patients' meaningmaking processes, despite the situation, is an important health-promoting concern. Often the way to meaning goes through what the individual has managed, accomplished, contributed to, intended, and tolerated in their life ("life review") - through acceptance of who one is and one's life as it is. To integrate their lives in this way, most people need a relationship, one who listens, acknowledges, and affirms [115]. Thus, the nurse-patient relationship emerges as a significant resource for patient's meaning-in-life. Studies have shown that the nurse-patient interaction has a significant influence on nursing home resident's perceived meaning; the good "meeting" facilitating meaning is perceived as soothing and empowering [11, 93, 105, 116]. Meaning is also created by experiences of something good and beautiful, by self-transcendence, and by choosing positive and caring attitudes amid a painful and difficult situation. To facilitate and support patient's meaning-making, a relationship supported by health-promoting interaction should be provided $[89,105]$. Figure 8.3 demonstrates that the three levels of body-mind-spirit interacting with each other are influenced by nurse-patient interaction: patients are affected physically, psychologically, socially, and spiritually-existentially. Health-promoting interaction impacts the patient as body-mind-spirit supporting his search for "his" meaning. However, we do not state that the nurse-patient interaction is the only way to 


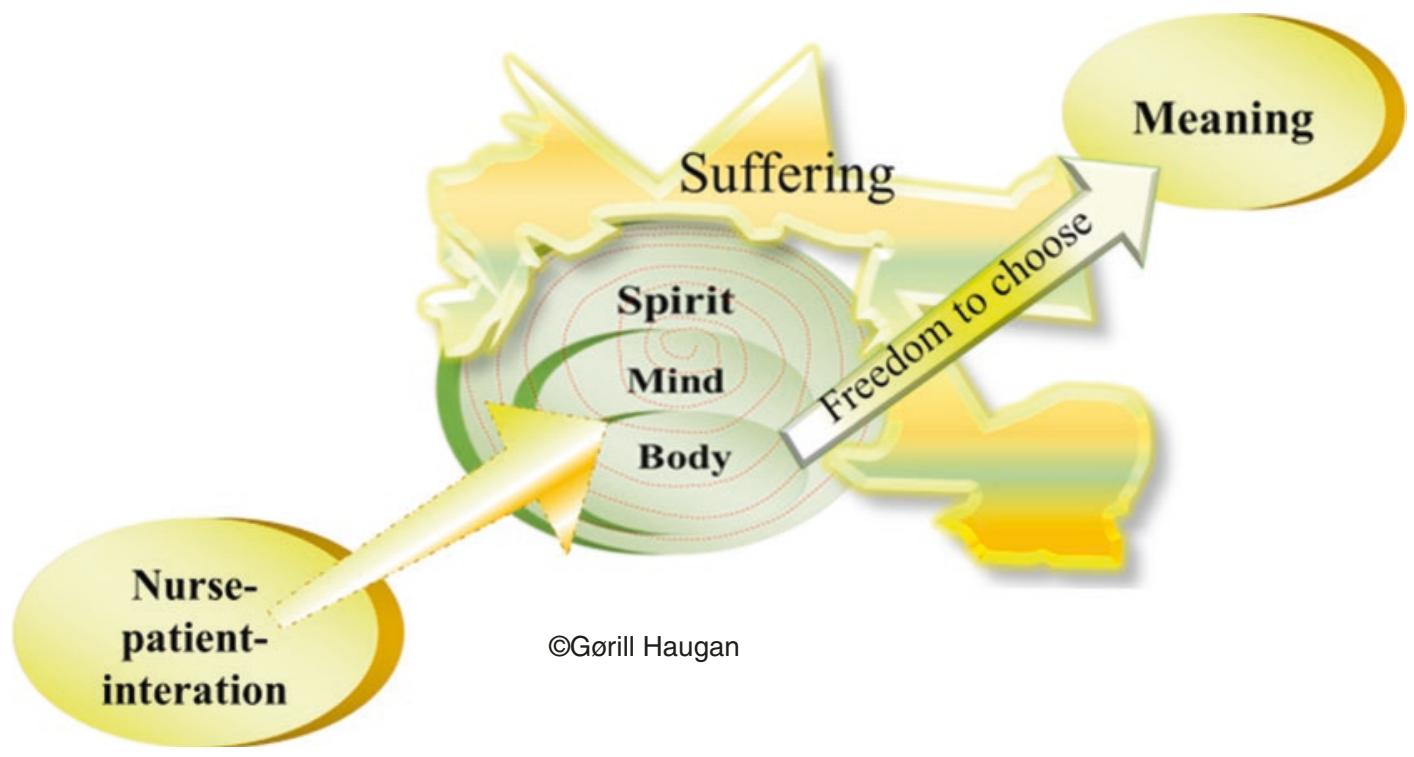

Fig. 8.3 Nurse-patient interaction affects all the three levels of body-mind-spirit and is a vital health promoting resource in facilitating patient's meaning-making processes. Nurses and health care professionals can support

facilitate and support patients' meaning-making processes. Though, to our knowledge, the nursepatient interaction is a key resource to support meaning in the context of health care.

Finally, health care professionals need to reflect on what gives perceived meaning in their daily work, in life, and in the face of serious illness and death. The professionals too need a conscious attention to meaning in their own life: who you are and why you are right here. This will promote health for the individual health worker, but also constitute a significant aspect of competence as professional health workers.

\section{Take Home Messages}

- Perceived meaning-in-life is essential for people's psychological functioning and is one of the core elements of positive psychology as well as health-promoting research and work.

- In the salutogenic health theory, meaning is the motivating dimension in the threedimensional concept "sense of coherence."

- Perceived meaning-in-life is a strong individual predictor of satisfaction with life, as thus patients' meaningfulness in different ways. However, in the context of nursing and health care, the nurse-patient interaction has shown to be a key salutogenic resource in supporting patients' meaning-making processes

crucial to psychological well-being; a buffer that contributes to inner strength and thereby protects the individual from depression, hopelessness, and the urge to give up.

- Positive associations between meaning-in-life and psychological well-being have been found across the lifespan, including adolescence, emerging adulthood, midlife, and older adulthood.

- Studies have shown a significant relationship between meaning-in-life and physical health measured by lower mortality for all causes of death; meaning is significantly correlated with less cardiovascular disease, less hypertension, better immune function, less depression and better coping with illness, crises and death, as well as better recovery from illness.

- Patients who find meaning despite illness, ailments, and imminent death experience more well-being and better health and quality-oflife in their life situation.

- Frankl's logotherapy emphasizes the spiritual dimension of the human life; the need for meaning arises from the existential consciousness of life and death. 
- Frankl's theory of meaning is based on three substantial concepts: (1) meaning-in-life, (2) freedom to choose, and (3) suffering.

- Frankl outlines three different sources of meaning: (1) performing good deeds; to give or contribute something good or useful, or through one's creativity to create something beautiful, (2) to experience something valuable and beautiful-to experience kindness and loving fellowship, and (3) to realize dignified, honorable, and positive attitudes in meeting with life's challenges, such as illness, suffering, and death.

- Health care professionals can facilitate and support patients' search for meaning by offering a relationship where the patient's experiences, thoughts, and emotions are attended to.

- Acceptance is healing and health-promoting by providing inner peace and tranquility and thus releases energy to experience positive aspects of life here-and-now.

\section{References}

1. King LA, Hicks J, Krull J, Del Gaiso A. Positive affects and the experience of meaning in life. J Pers Soc Psychol. 2006;90:179-96.

2. Wong P, Fry P. The human quest for meaning: a handbook of psychologicasl research and clinical applications. Mahwah, NJ: Lawrence Erlbaum Associates Publishers; 1998.

3. Schulenberg SE, Hutzell R, Nassif C, Rogina J. Logotherapy for clinical practice. Psychother Theor Res Pract Train. 2009;45(4):447-63.

4. Peterson C, Park N, Seligman M. Orientations to happiness and life satisfactiom: the full life versus the empty life. J Happiness Stud. 2005; $6: 25-41$.

5. Morgan J, Farsides T. Measuring meaning in life. J Happiness Stud. 2009;10(2):197-214.

6. Seligman MEP. Authentic happiness. New York: Free Press; 2002.

7. Bonebright C, Clay D, Ankenmann R. The relationship of workaholism to work-life conflict, life satisfaction and purpose in life. J Couns Psychol. 2000;47:469-77.

8. Fry P. The unique contribution of key existential factors to the prediction of psychological Well-being of older adults following spousal loss. Gerontologist. 2001;41:69-81.

9. Melton A, Schulenberg S. On the measurement of meaning; Logotherapy's empirical contribu- tions to humanistic psychology. Humanist Psychol. 2008;36:31-44.

10. Pearson P, Sheffield B. Psychoticism and purpose in life. Personal Individ Differ. 1989;10:1321-2.

11. Haugan Hovdenes G. The nurse-patient-relationship in nursing homes: fulfillment or destruction [Pleierpasient-relasjonen i sykehjem: virkeliggjørelse eller tilintetgjørelse]. Nord J Nurs Res Clin Stud. 2002;22(3):21-6.

12. Kleftaras G, Psarra E. Meaning in life, psychological well-being and depressive symptomatology: a comparative study. Psychol Forsch. 2012;3(4):337-45.

13. Chan DW. Orientations to happiness and subjective well-being among Chinese prospective and in-service teachers in Hong Kong. Educ Psychol. 2009;29:139-51.

14. Halama P, Dedova M. Meaning in life and hope as predictors of positive mental health: do they explain residual variance not predicted by personality traits? Stud Psychol. 2007;49:191-200.

15. Ho MY, Cheung FM, Cheung SF. The role of meaning in life and optimism in promoting well-being. Personal Individ Differ. 2010;48:658-63.

16. Holahan CK, Holahan CJ, Suzuki R. Purposiveness, physical activity, and perceived health in caridac patients. Disabil Rehabil. 2008;30:1772-8.

17. Frankl VE. Man's search for meaning. New York: Washington Square Press; 1963.

18. Frankl VE. The will to live. 1963.

19. Frankl VE. The unheard cry for meaning. New York: Simion \& Scuster; 1978.

20. Melton A, Schulenberg S. On the relationship between meaning in life and boredom proneness: examining a logotherapy postulate. Psychol Rep. 2007;101:1016-22.

21. Pöhlmann K, Gruss B, Joraschky P. Structural properties of personal meaning systems: a new approach to measuring meaning in life. J Posit Psychol. 2006;1:109-17.

22. Starck PL. Theory of meaning. In: Smith MJ, Liehr PR, editors. Middel range theory for nursing. 2nd ed. New York: Springer, LLC; 2008. p. 81-104.

23. Antonovsky A. Health, stress, and coping: new perspectives on mental health and physical wellbeing. San Francisco: Jossey-Bass; 1979.

24. Antonovsky A. Unraveling the mystery of health. How people manage stress and stay well. San Fransisco: Jossey-Bass; 1987.

25. Skarsater I, Rayens M, Peden A, Hall L, Zhang M, Agren $H$, et al. Sense of coherence and recovery from major depression: a 4-year follow-up. Arch Psychiatr Nurs. 2009;23:119-27.

26. Zirke N, Schmid G, Mazurek B, Klapp B, Rauchfuss M. Antonovsky's Sense of Coherence in psychosomatic patients - a contribution to construct validation. GMS Psycho Soc Med. 2007;4:Doc03.

27. Pallant J, Lae L. Sense of coherence, well-being, coping and personality factors: further evaluation of 
the sense of coherence scale. Personal Individ Differ. 2002;33:39-48.

28. Eriksson M, Lindstrom B. Antonovsky's sense of coherence scale and its relation with quality of life: a systematic review. J Epidemiol Community Health. 2007;61:938-44.

29. Surtees P, Wainwright N, Luben R, Khaw K, Nicholas D. Sense of coherence and mortality in men and women in the EPIC-Norfolk United Kingdom Prospective Cohort Study. Am J Epidemiol. 2003;158:1202-9.

30. Yalom I. Existential psychotherapy. New York: Basic Books; 1980.

31. Steger MF. An illustration of issues in factor extraction and indentification of dimensionality in psychological assessment data. J Pers Assess. 2006;86:263-72.

32. Roepke A, Jayawickreme E, Riffle O. Meaning and health: a systematic review. Appl Res Qual Life. 2014;9(4):1055-79.

33. Baumeister R. Meanings in life. New York: Guilford; 1991.

34. Heintzelman S, King L. (The feeling of) meaning-as-information. Pers Soc Psychol Rev. 2014;18:153-67.

35. George L, Park C. Are meaning and purpose distinct? An examination of correlates and predictors. J Posit Psychol. 2013;8:365-75.

36. Steger MF, Frazier P, Oishi S, Kaler M. The meaning in life questionnaire: assessing the presence of and search for meaning in life. J Couns Psychol. 2006;53:80-93.

37. McKnight P, Kashdan T. Purpose in life as a system that creates and sustains health and well-being: an integrative, testable theory. Rev Gen Psychol. 2009;13:242-51.

38. Martela F, Steger MF. The three meanings of meaning in life: distinguishing coherence, purpose, and significance. J Posit Psychol. 2016;11(5):531-45.

39. George L, Park C. Meaning in life as comprehension, purpose, and mattering: toward integration and new research questions. Rev Gen Psychol. 2016;20:205-20.

40. Haugan G. Meaning-in-life in nursing-home patients: a valuable approach for enhancing psychological and physical well-being? J Clin Nurs. 2014;23(13-14):1830-44.

41. Brassai L, Piko B, Steger M. Meaning in life: is it a protective factor for adolescents' psychological health? Int J Behav Med. 2011;18(1):44-51.

42. Steger MF, Oishi S, Kashdan TB. Meaning in life across the life span: levels and correlates of meaning in life from emerging adulthood to older adulthood. J Posit Psychol. 2009;4(1):43-52.

43. Zika S, Chamberlain K. On the relation between meaning in life and psychological well-being. Br J Psychol. 1992;83:133-45.

44. Schulenberg SE, Hutzell R, Nassif C, Rogina J. Logotherapy for clinical practice. Psychother Theor Res Pract Train. 2008;45:447-63.
45. Moore SL, Metcalf B, Schow E. Aging and meaning in life: examining the concept. Geriatr Nurs. 2000;21(1):27-9.

46. Sarvimäki A, Stenbock-Hult B. Quality of life in old age described as a sense of well-being, meaning and value. J Adv Nurs. 2000;32(4):1025-33.

47. Wang J-J. A structural model of the bio-psychosocio-spiritual factors influencing the development towards gerotranscendence in a sample of institutionalized elders. J Adv Nurs. 2011;67(12):2628-36.

48. Koenig HG, George LK, Titus P, Meador KG. Religion, spirituality, and acute care hospitalization and long-term care use by older patients. Arch Intern Med. 2004;164(14):1579-85.

49. Krause N. Longitudinal study of social support and meaning in life. Psychol Aging. 2007;22(3):456-69.

50. Krause N. Meaning in life and mortality. J Gerontol B Psychol Sci Soc Sci. 2009;64B(4):517-27.

51. Starkweather A, Wiek-Janusek L, Mathews H. Applying the psychoneuroimmunology framework to nursing research. $J$ Neurosci Nurs. 2005;37(1):56-62.

52. Vance DE, Struzick TC, Raper JL. Biopsychosocial benefits of spirituality in adults aging with HIV. J Holist Nurs. 2008;26(2):119-25.

53. Westerhof GJ, Bohlmeijer ET, van Beljouw IMJ, Pot AM. Improvement in personal meaning mediates the effects of a life review intervention on depressive symptoms in a randomized controlled trial. Gerontologist. 2010;50(4):541-9.

54. Haugan G. Meaning-in-life in nursing-home patients: a correlate to physical and emotional symptoms. J Clin Nurs. 2014;23(7-8):1030-43.

55. William B, Christopher G, Poppito Shannon R, Amy B. Psychotherapeutic interventions at the end of life: a focus on meaning and spirituality. Can J Psychiatry. 2004;49(6):366-72.

56. Breitbart W, Rosenfeld B, Gibson C, Pessin H, Poppito S, Nelson C, et al. Meaning-centered group psychotherapy for patients with advanced cancer: a pilot randomized controlled trial. Psychooncology. 2010;19(1):21-8.

57. Fitchett G, Canada AL. The role of religion/spirituality in coping with cancer: evidence, assessment, and inervention. In: Holland JC, Breitbart WS, Jacobsen PB, editors. Psychooncology. 2nd ed. New York: Oxford University Press; 2010. p. 440-6.

58. Alpers L-M, Helseth S, Bergbom I. Experiences of inner strength in critically ill patients-a hermeneutical approach. Intensive Crit Care Nurs. 2012;28(3):150-8.

59. Alexandersen I, Stjern B, Eide R, Haugdahl H, Paulsby $\mathrm{T}$, Lund $\mathrm{S}$, et al. "never in my mind to give up!" a qualitative study of long-term intensive care patients' inner strength and willpowerpromoting and challenging aspect. J Clin Nurs. 2019;28(21-22):3991-4003.

60. Dezutter J, Luyckx K, Wachholtz A. Meaning in life in chronic pain patients over time: associations 
with pain experience and psychological well-being. J Behav Med. 2015;38(2):384-96.

61. Kissane DW, Clarke DM, Street AF. Demoralization syndrome: a psychiatric diagnosis for palliative care. J Palliat Care. 2001;17(1):12-21.

62. Parker ME. Medicalizing meaning: demoralization syndrome and the desire to die. Aust N Z J Psychiatry. 2003;38(10):765-73.

63. Pinquart M. Creating and maintaining purpose in life in old age: a meta-analysis. Aging Int. 2002;27:90-104.

64. Hedberg P, Brulin C, Aléx L, Gustafson Y. Purpose in life over a five-year period: a longitudinal study in a very old population. Int Psychogeriatr. 2011;23(5):806-13.

65. Flood M. Exploring the relationships between creativity, depression, and successful aging. Activit Adapt Aging. 2007;31(1):55-71.

66. Flood M, Scharer K. Creativity enhancement: possibilities for successful aging. Issues Ment Health Nurs. 2006;27:939-59.

67. Angel S. The fight for a meaningful life [Danish]. Sygeplejersken/Danish J Nurs. 2009;109(17):48-53.

68. Dossey B, Keegan L, editors. Holistic nursing: a handbook for practice. London: Jones and Bartlett; 2009.

69. Travelbee J. Interpersonal aspects of nursing. 2nd ed. Philadelphia: F.A. Davis; 1979.

70. Park C, Folkman S. Meaning in the context of stress and coping. Rev Gen Psychol. 1997;1:115-44.

71. Reker G, Wong P. Aging as an individual process: toward a theory of personal meaning. In: Birren J, Bengston V, editors. Emergent theories of aging. New York: Springer; 1988.

72. Nolen-Hoeksema S, Davis C. Theoretical and methodological issues in the assessment and interpretation of posttraumatic growth. Psychol Inq. 2004; 15:60-4.

73. Kennedy-Moore E, Watson J. How and when does emotional expression help? Rev Gen Psychol. 2001:187-212.

74. Park CL. Making sense of the meaning literature: an integrative review of meaning making and its effects on adjustment to stressful life events. Psychol Bull. 2010;136(2):257-301.

75. Janoff-Bulman R. Posttraumatic growth: three explanatory models. Psychol Inq. 2004;15(1):30-4.

76. Antonovsky A. Unraveling the mystery of health: how people manage stress and stay well. San Fransisco: Jossey-Bass; 1987.

77. Dwyer L, Nordenfelt L, Ternestedt B-M. Three nursing home residents speak about meaning at the end of life. Nurs Ethics. 2008;15(1):97-109.

78. Knestrick J, Lohri-Posey B. Spirituality and health: perceptions of older women in a rural senior high rise. J Gerontol Nurs. 2005;31(10):44-50; quiz 1-2.

79. Thomas JC, Burton M, Quinn Griffin MT, Fitzpatrick JJ. Self-transcendence, spiritual well-being, and spiritual practices of women with breast cancer. J Holist Nurs. 2010;28(2):115-22.
80. Van Orden K, Bamonti P, King D, Duberstein P. Does perceived burdensomeness erode meaning in life among older adults? Aging Ment Health. 2012;16(7):855-60.

81. Sulmasy D. A biopsychological-spiritual model for the care of patients at the end of life. Gerontologist. 2002;2002(Special Issue III):24-33.

82. Rannestad T, Hovdenes GH, Espnes GA. Hjernen er ikke alene: psykosomatikken ser kropp og sjel i sammenheng, det bør sykepleie også gjøre; Tidsskriftet Sykepleien [Norwegian Journal of Nursing], 2006. p. 52-6.

83. Astrow A, Puchalski C, Sulmasy D. Religion, spirituality, and health care: social, ethical, and practical considerations. Am J Med. 2001;110(4):283-7.

84. Moore L, Goldner-Vukov M. The existential way to recovery. Psychiatr Danub. 2009;4:453-62.

85. Silver C, Bernaud J, Pedersen H, Birkeland M, la Cour P, Schnell T. Three cultural comparisons and inferences using the Sources of Meaning and Meaning in Life Questionnaire. The biannual meeting of the International Society for Psychology of Religion; Lausanne, Switzerland; 2013.

86. Dezutter J, Offenbaecher M, Vallejo MA, Vanhooren S, Thauvoye E, Toussaint L. Chronic pain care: the importance of a biopsychosocial-existential approach. Int J Psychiatry Med. 2016;51(6): 563-75.

87. Spiegelberg E. The phenomenological movement: a historical introduction. Dordrect, Boston, London: Kluwer Academic; 1994.

88. Guzzetta CE. Holistic nursing research. In: Dossey BM, Keegan L, Guzzetta CE, editors. Holistic nursing a handbook for practice. 4th ed. Boston, Toronto, London, Singapore: Jones and Bartlett; 2009. p. 211-28.

89. Haugan G. Life satisfaction in cognitively intact long-term nursing-home patients: symptom distress, well-being and nurse-patient interaction. Chapter 10 In: Sarracino F, Mikucka M, editors. Beond money: the social roots of health and well-being. New York: Nova Science; 2014. p. 165-211.

90. Haugan G, Demirci AD, Kukulu K, Aune I. Selftranscendence in individuals 65 years and older: A meta-analysis. Scand J Caring Sci. 2021. https://doi. org/10.1111/scs.12959.

91. Reed PG, Haugan G. Self-transcendence - a salutogenic resource. Chapter 9 In: Haugan G, Eriksson M, editors. Health promotion in health care-vital theories and research. London: Springer; 2021.

92. Boyraz G, Horne SG, Sayger TV. Finding meaning in loss: the mediating role of social support between personality and two construals of meaning. Death Stud. 2012;36(6):519-40.

93. Haugan G. The relationship between nursepatient-interaction and meaning-in-life in cognitively intact nursing-home patients. J Adv Nurs. 2014;70(1):107-20.

94. Haugan G, Innstrand ST, Moksnes UK. The effect of nurse-patient-interaction on anxiety and depression 
in cognitively intact nursing home patients. $\mathrm{J}$ Clin Nurs. 2013;22(15-16):2192-205.

95. Haugan G. Nurse-patient interaction is a resource for hope, meaning-in-life, and self-transcendence in cognitively intact nursding-home patients. Scand J Caring Sci. 2014;2014(28):74-8.

96. Frankl VE. Man's search for meaning: the classic tribute to hope from the holocaust: SD Books; 2008.

97. WHO. Depression in Europe. 2012. http://www. euro.who.int/en/health-topics/noncommunicable-diseases/mental-health/news/news/2012/10/ depression-in-europe.

98. Lee V, Cohen SR, Edgar L, Laizner AM, Gagnon AJ. Meaning-making intervention during breast or colorectal cancer treatment improves selfesteem, optimism, and self-efficacy. Soc Sci Med. 2006;62(12):3133-45.

99. Lee V. The existential plight of cancer: meaning making as a concrete approach to the intangible search for meaning. Support Care Cancer. 2008;16(7):779-85.

100. Mohabbat-Bahar S, Golzari M, Moradi-Joo M, Akbari ME. Efficacy of group Logotherapy on decreasing anxiety in women with breast cancer. Iran J Cancer Prev. 2014;7(3):165-70.

101. Keall RM, Clayton JM, Butow PN. Therapeutic life review in palliative care: a systematic review of quantitative evaluations. J Pain Symptom Manage. 2015;49(4):747-61.

102. Simpson DB, Newman JL, Fuqua DR. Spirituality and personality: accumulating evidence. J Psychol Christ. 2007;26(1):33-44.

103. Haugan Hovdenes G. Troen, håpet og kjærligheten: avgjørende ressurser relatert til helse og livskvalitet. Munksgaard; 1995. p. 97-101.

104. Mwilambwe-Tshilobo L, Ge T, Chong M, Ferguson M, Misic B, Burrow A, et al. Loneliness and meaning in life are reflected in the intrinsic network architecture of the brain. Soc Cogn Affect Neurosci. 2019;14(4):423-33.

105. Haugan G. Nurse-patient interaction-a vital health promoting resource in nursing homes. Chapter $10 \mathrm{In}$ : Haugan G, Eriksson M, editors. Health promotion in health care-vital theories and research. London: Springer; 2021.

106. Milberg A, Strang P. What to do when 'there is nothing more to do'? A study within a salutogenic framework of family members' experience of palliative home care staff. Psychooncology. 2007;16(8):741-51.

107. Arman M. Bearing witness: an existential position in caring. Contemp Nurse. 2007;27(1):84-93.

108. Drageset J, Eide G, Kirkevold M, Ranhoff A. Emotional loneliness is associated with mortality among mentally intact nursing home residents with and without cancer: a five-year follow-up study. J Clin Nurs. 2013;22(1-2):106-14.

109. Nåden D, Sæteren B. Cancer patients' perception of being or not being confirmed. Nurs Ethics. 2006;13(3):222-35.

110. Haugan G, Hanssen B, Rannestad T, Espnes GA. Self-transcendence and nurse-patient interaction in cognitively intact nursing-home patients. $\mathrm{J}$ Clin Nurs. 2012;21:3429-41.

111. Haugan G, Rannestad T, Hammervold R, Garåsen $\mathrm{H}$, Espnes GA. Self-transcendence in nursing home patients-a resource for well-being. J Adv Nurs. 2013;69(5):1147-60.

112. Moksnes UK, Espnes GA, Haugan G. Stress, sense of coherence, and emotional symptoms in adolescents. Psychol Health. 2014;29(1):32-49.

113. Moksnes U, Haugan G. Validation of the orientation to Life Questionnaire in Norwegian adolescents, construct validity across samples. Soc Indic Res. 2013; https://doi.org/10.1007/s11205-013-0536-z.

114. Moksnes UK. Sense of coherence. In: Haugan G, Eriksson M, editors. Health promotion in health care-vital theories and research. London: Springer; 2021. p. 20.

115. Kagan PN. Feeling listened to: a lived experience of Humanbecoming. Nurs Sci Q. 2008;21(1):59-67.

116. Jonas-Simpson C, Mitchell GJ, Fisher A, Jones G, Linscott J. The experience of being listened to: a qualitative study of older adults in long-term care settings. J Gerontol Nurs. 2006;32(1):46-53.

Open Access This chapter is licensed under the terms of the Creative Commons Attribution 4.0 International License (http://creativecommons.org/licenses/by/4.0/), which permits use, sharing, adaptation, distribution and reproduction in any medium or format, as long as you give appropriate credit to the original author(s) and the source, provide a link to the Creative Commons license and indicate if changes were made.

The images or other third party material in this chapter are included in the chapter's Creative Commons license, unless indicated otherwise in a credit line to the material. If material is not included in the chapter's Creative Commons license and your intended use is not permitted by statutory regulation or exceeds the permitted use, you will need to obtain permission directly from the copyright holder.

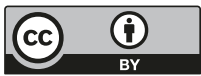

